\title{
Controle DE Commelina benghalensis, C. erecta e Tripogandra diuretica NA CULTURA DO CAFÉ ${ }^{1}$
}

\author{
Interference of Dayflower Species in Coffee Culture \\ OLIVEIRA, A.R. ${ }^{2}$, FREITAS, S.P. ${ }^{3}$ e VIEIRA, H.D. ${ }^{3}$
}

\begin{abstract}
RESUMO - O objetivo deste trabalho foi avaliar o efeito de diferentes herbicidas/misturas no controle de três espécies de trapoeraba (Commelina benghalensis, C. erecta e Tripogandra diuretica) e a tolerância de plantas jovens de café aos herbicidas. O delineamento experimental foi inteiramente casualizado, com quatro repetições. Os tratamentos foram constituídos por dez diferentes herbicidas/misturas e uma testemunha, associados a três espécies de trapoeraba. As avaliações foram realizadas aos 21 e 50 dias após a aplicação (DAP) dos herbicidas, por meio de análise visual, seguindo-se escala de nível de controle. Avaliou-se a tolerância das mudas de café aos herbicidas (escala de avaliação visual da fitotoxicidade) e as características de crescimento (diâmetro, número de folhas e estatura) das mudas de café. A espécie $C$. benghalensis foi melhor controlada quando se utilizaram os herbicidas: diuron, 2,4-D + picloram, atrazine + metolachlor, metribuzin, glyphosate WG e acetochlor. A espécie C. erecta foi controlada pelos herbicidas diuron, 2,4-D + picloram, atrazine + metolachlor, glyphosate CS e acetochlor. Os herbicidas diuron, 2,4-D + picloram, atrazine + metolachlor, metribuzin, glyphosate WG e paraquat + diuron foram os que melhor controlaram T. diuretica. Metribuzin, diuron e acetochlor mostraram-se mais fitotóxicos para a cultura do café. O diuron reduziu a massa da matéria seca e o número de folhas do cafeeiro. O diâmetro do caule e a estatura foram afetados pelos herbicidas metribuzin e 2,4-D. O metribuzin foi o herbicida que maior prejuízo causou às características de crescimento da planta de café.
\end{abstract}

Palavras-chave: Commelinaceae, controle químico, Coffea arabica, herbicida.

\begin{abstract}
This work aimed to evaluate the effect of different herbicides/mixtures on the control of three dayflower species (Commelina benghalensis, C. erecta. and Tripogandra diuretica) and the tolerance of young coffee plants to the herbicides. The trial was arranged in a completely randomized design, constituted by ten different herbicides/mixtures and three dayflower species. Evaluations were carried out at 21 and 50 days after herbicide application (DAP), using visual analysis, following a control level scale. Coffee seedling tolerance to the herbicides (visual scale evaluation of phytotoxicity) and growth characteristics (diameter, number of leaves and height) of the coffee seedlings were evaluated. C. benghalensis was better controlled by diuron, 24-D + picloram, atrazine + metolachlor, metribuzin, glyphosate $W G$ and acetochlor. C. erecta was controlled by diuron, 2, 4-D + picloram, atrazine metolachlor, glyphosate SC and acetochlor. Diuron, 2, 4-D + picloram, atrazine + metolachlor, metribuzin, glyphosate WG and paraquat diuron controlled $\boldsymbol{T}$. diuretica the best. Metribuzin, diuron and acetochlor were more phytotoxic to the coffee crop. Diuron reduced dry matter weight and number ofleaves of the coffee plant. Stem diameter and height were affected by the herbicides metribuzin and 2,4-D. Metribuzin caused the most damage to the growth characteristics of the coffee seedlings.
\end{abstract}

Keywords: Commelinaceae, chemical control, Coffea arabica, herbicide.

Recebido para publicação em 17.12.2008 e na forma revisada em 13.11.2009

2 Engô-Agr ${ }^{-}$., Dr. em Produção Vegetal, Pesquisador da Embrapa Semi-árido, BR 428, km 152, Zona Rural, Caixa Postal 23, 56302-970 Petrolina-PE, <anderson.oliveira@cpatsa.embrapa.br>; ${ }^{3}$ Engํ-Agr ${ }^{\circ}$., Dr., Prof., Laboratório de Fitotecnia/CCTA, Universidade Estadual do Norte Fluminense Darcy Ribeiro - UENF, <silverio@uenf.br>, <henrique@uenf.br>.

Planta Daninha, Viçosa-MG, v. 27, n. 4, p. 823-830, 2009 


\section{INTRODUÇÃO}

A cultura do café (Coffea arabica) apresenta grande importância econômica, política e social no Brasil. A produção nacional da safra 2007/2008 foi de, aproximadamente, 45,9 mil sacas de $60 \mathrm{~kg}$ de café beneficiado, sendo 35,4 mil sacas de arábica e 10,5 mil de robusta, superior à safra 2006/2007 em 27,5\%, em razão da bienalidade (CONAB, 2008). Diante da relevância dessa atividade, verifica-se a necessidade de adotar práticas que garantam a produtividade da cultura, destacando-se entre elas o controle de plantas daninhas.

Um dos grandes problemas relacionados com a cafeicultura é a interferência das plantas daninhas, principalmente durante a implantação da lavoura. A competição afeta as plantas, alterando estatura, diâmetro do caule, número de folhas e absorção de nutrientes (Ronchi et al., 2003; Dias et al., 2004, 2005; Oliveira et al., 2005; Ronchi \& Silva, 2006). O potencial de competição das plantas daninhas com as plantas de café é elevado, sobretudo durante a fase de implantação da cultura, pois a capacidade das plantas invasoras em absorver água e nutrientes é muito maior comparativamente (Toledo et al., 1996; Dias et al., 2004). A capacidade de absorção de alguns nutrientes minerais ( $\mathrm{N}, \mathrm{P}$ e $\mathrm{K})$, em algumas espécies de plantas daninhas, é cerca de 5 a 15 vezes a capacidade do café (Ronchi et al., 2003).

Observa-se, nas áreas tratadas com herbicidas, a seleção de espécies tolerantes, principalmente ao glyphosate. Entre as espécies de plantas daninhas que têm apresentado tolerância às aplicações de glyphosate, destaca-se a trapoeraba: Commelina benghalensis, C. diffusa, C. erecta, C. nudiflora (Tuffi Santos et al., 2004; Monquero et al., 2005; Rocha et al., 2007) e Tripogandra diuretica. Vargas et al. (1999) relatam que a espécie Commelina spp. apresenta alta tolerância aos inibidores da enzima EPSPs (5-enol-piruvil shiquimato-3fosfato sintase), como o glyphosate. Especulase que essa tolerância esteja relacionada com a insensibilidade da EPSPs dessas espécies aos herbicidas. Há, portanto, necessidade de conhecer melhor o comportamento das espécies supramencionadas quando tratadas com outros herbicidas, com o objetivo de selecionar produtos e/ou misturas de produtos que sejam eficientes no controle dessas espécies.

Vários estudos têm sido desenvolvidos para o controle de trapoerabas. Tozani et al. (1995) constataram que houve controle de trapoerabas (Commelina spp.) quando se utilizaram doses de $800 ; 1.600$ e 2.400 g i.a. ha ${ }^{-1}$ do herbicida diuron, em trabalho desenvolvido na cultura do arroz de sequeiro. Ramos \& Durigan (1996) alcançaram excelente controle de $C$. benghalensis com a mistura pronta de $2,4-\mathrm{D}+$ glyphosate $\left(600+800\right.$ g i.a. ha $\left.{ }^{1}\right)$ em pós-emergência, quando a espécie já florescia e tinha altura variável entre 15 e $60 \mathrm{~cm}$. De La Vega et al. (2000) obtiveram excelente resultado com o uso de glyphosate em pósemergência ( $1.494 \mathrm{~g}$ i.a. $\left.\mathrm{ha}^{-1}\right)$ no controle de C. erecta, alcançando $100 \%$ de mortalidade da invasora. Em trabalho de Monquero et al. (2005), observou-se que tratamentos com glyphosate nas doses de 360 e 540 g i.a. ha ${ }^{-1}$ causaram leve toxicidade aos 28 dias após a aplicação (10 a $18 \%$ de controle) e que nas doses de 1.440 e 2.160 g i.a. ha ${ }^{-1}$ o controle foi apenas aceitável: na faixa de 71 a $85 \%$ de C. benghalensis. Sullivan \& Donovan (2006) relataram que o uso da mistura de 2,4-D + glyphosate aumenta a porcentagem de controle da espécie daninha, pois esses herbicidas danificam os vasos condutores e afetam a translocação dos produtos na planta.

A aplicação de herbicidas em área total, na fase de implantação da cultura do café, requer que os produtos utilizados apresentem seletividade à cultura. Contudo, de acordo com Ronchi et al. (2001), a maioria dos herbicidas registrados para a cultura de café não apresenta seletividade para serem aplicados diretamente sobre as plantas. Em trabalho desenvolvido por Ronchi \& Silva (2003), observou-se que a mistura pronta de fluazifop-pbutil + fomesafen $\left(240+200\right.$ g i.a. ha $\left.{ }^{-1}\right)$ causou toxicidade moderada às plantas de café 70 dias após a aplicação e o metribuzin na dose de 240 g i.a. ha ${ }^{-1}$ causou fitotoxicidade muito forte para as mudas de café. A suscetibilidade do cafeeiro aos herbicidas pode ser momentânea. Rocha \& Silva (1999) observaram que a aplicação do herbicida acetochlor em doses de 2,0, 3,0 e 4,0 $\mathrm{L} \mathrm{ha}^{-1}$ diretamente sobre as plantas de café provocou fitotoxidade, que foi reduzida aos 40 dias após a aplicação. 
Assim, o objetivo deste trabalho foi avaliar a eficiência de diferentes herbicidas/misturas no controle de Commelina benghalensis, C. erecta e Tripogandra diuretica, bem como a tolerância de plantas jovens de café aos herbicidas.

\section{MATERIAL E MÉTODOS}

O estudo foi desenvolvido na Estação Experimental da PESAGRO, no município de Campos dos Goytacazes-RJ, com altitude de $13 \mathrm{~m}$, tendo como coordenadas geográficas $21^{\circ} 45^{\prime} 15^{\prime \prime}$ de latitude sul e $41^{\circ} 19^{\prime} 28^{\prime \prime}$ de longitude oeste. O clima da região é classificado, segundo Köppen, como Awi, com temperatura média em torno de $24^{\circ} \mathrm{C}$ e precipitação anual de $905 \mathrm{~mm}$, em quatro repetições.

As mudas de café (Coffea arabica cultivar Catuaí Vermelho) foram adquiridas em viveiro registrado no Ministério da Agricultura, Pecuária e Abastecimento, localizado no município de Cachoeiro de Itapemirim- ES, no estádio de seis folhas definitivas. Essas mudas foram transferidas para vasos plásticos com capacidade de 5 litros de substrato, juntamente com os propágulos das espécies de trapoeraba. Utilizaram-se seis ramos (propágulos) por vaso. Cada ramo apresentava-se em média com 6 a 10 gemas.

Cada unidade experimental foi constituída por um vaso. O substrato foi composto de duas partes de areia, uma parte de terra e uma de esterco curtido, cujas características físicas e químicas foram as seguintes: $614,0 \mathrm{~g} \mathrm{~kg}^{-1} \mathrm{de}$ areia; $158,0 \mathrm{~g} \mathrm{~kg}^{-1}$ de silte; $228,4 \mathrm{~g} \mathrm{~kg}^{-1}$ de argila; 6,3 de $\mathrm{pH}$ em água; $32,4 \mathrm{~g} \mathrm{~kg}^{-1}$ de $\mathrm{MO}$; 2,4 $\mathrm{cmol}_{\mathrm{c}} \mathrm{dm}^{-3}$ de Ca; 2,2 $\mathrm{cmol}_{\mathrm{c}} \mathrm{dm}^{-3}$ de $\mathrm{Mg}$; $770,0 \mathrm{mg} \mathrm{dm}^{-3}$ de K; 83,0 mg dm ${ }^{-3}$ de P; e 83,7\% de saturação de base. Os vasos foram dispostos em terreno plano e sem cobertura e irrigados diariamente, procurando-se manter o solo com umidade próxima à capacidade de campo.

O delineamento experimental foi de blocos casualizados, em esquema fatorial $3 \times 11$, correspondendo, respectivamente, às espécies de trapoeraba ( $C$. benghalensis, $C$. erecta e T. diuretica) associadas aos herbicidas/misturas: fluazifop-p-butil + fomesafen $(180+$ 225 g i.a. ha $\left.{ }^{-1}\right)$, paraquat + diuron $(500+$ $250 \mathrm{~g}$ i.a. ha $\left.\mathrm{ha}^{-1}\right)$, atrazine + metolachlor $(1.400$ + 2.100 g i.a. ha-1), 2,4-D (1.800 g i.a. ha-1),
2,4-D + picloram $\left(480+130\right.$ g i.a. ha $\left.{ }^{-1}\right)$, diuron (2.400 g i.a. ha $\left.{ }^{-1}\right)$, metribuzin (720 g i.a. ha-1), glyphosate grânulos autodispersiveis (WG) (1.440 g i.a. ha ${ }^{-1}$ ); glyphosate concentrado solúvel (CS) (1.170 g i.a. ha ${ }^{-1}$ ), acetochlor (2.700 g i.a. ha $\left.{ }^{-1}\right)$ e testemunha sem aplicação de herbicida

Os herbicidas/misturas foram pulverizados sobre as mudas de café e sobre as espécies de trapoeraba, em uma única aplicação, realizada aos 30 dias após o transplantio das mudas para os vasos. Nessa fase, as espécies de trapoeraba cobriam toda a superficie do vaso e as mudas de café apresentavam-se com aproximadamente 12 folhas definitivas. Na aplicação dos produtos utilizou-se pulverizador pressurizado com $\mathrm{CO}_{2}$ provido de bico tipo leque Teejet 80015 e volume de calda de, aproximadamente, 200 litros por hectare. As aplicações dos herbicidas foram feitas nas primeiras horas do dia. As condições climáticas no dia da aplicação eram as seguintes: umidade relativa de $72,3 \%$, temperatura do ar de $17,0{ }^{\circ} \mathrm{C}$, radiação de $189 \mathrm{~W} \mathrm{~m}^{2}$ e velocidade do vento de $1,3 \mathrm{~m} \mathrm{~s}^{-1}$.

As avaliações de controle das três espécies de trapoeraba foram realizadas aos 21 e 50 dias após a aplicação (DAP) dos herbicidas/ misturas, por meio de análise visual, detectando-se alterações de coloração, ocorrência de manchas, murchamento, necroses, morte e outros sintomas, seguindo-se escala de nível de controle proposta por Deuber (1992), que é dividida em dez classes, de acordo com a porcentagem de controle. A classe 1 ( 0 a 10\%) considera o controle nulo, e a classe 10 (91 a $100 \%$ ) o considera muito bom.

Aos 21 e 50 DAP também foi avaliada a tolerância das mudas de café aos diferentes tratamentos, utilizando a escala de avaliação visual da fitotoxicidade. Essa escala, semelhante à escala de nível de controle, atribui valores de 1 a 10 aos danos causados às plantas de café pelos herbicidas em função da porcentagem de fitotoxidade: classe 1 ( 0 a $10 \%$ ), dano nulo; e classe 10 (91 a 100\%), dano total com morte da planta (Deuber, 1992). Aos 90 DAP, avaliaram-se as características de crescimento (diâmetro, número de folhas e estatura) das plantas de café, utilizando-se régua e paquímetro. Após as avaliações biométricas, as plantas de café foram cortadas rente ao solo, separando-se parte aérea (caule, 
ramos e folhas) e radicular. O substrato e a parte radicular das plantas de café foram separados com o auxílio de jatos de água. Após essa separação, tanto a parte aérea quanto a radicular foram pesadas. Para determinação da biomassa seca da parte aérea e radicular, as plantas foram acondicionadas em sacos de papel e colocadas em estufa com circulação forçada de ar, à temperatura média de $65^{\circ} \mathrm{C}$, até atingirem massa constante. Posteriormente, foram retiradas da estufa e, assim que atingiram a temperatura ambiente, foram pesadas em balança de precisão de $0,1 \mathrm{~g}$, para quantificação da massa seca.

Os dados obtidos foram submetidos às análises de variância. Para comparação de médias, utilizou-se o teste de Tukey a $5 \%$ de probabilidade.

\section{RESULTADOS E DISCUSSÃO}

A interação entre espécies de trapoeraba e herbicidas/misturas foi significativa, ou seja, a resposta ao controle depende da espécie tratada e do herbicida/mistura utilizado.

Observa-se que o tratamento com o herbicida diuron gerou resultados satisfatórios de controle da espécie daninha, posto que para as espécies $C$. benghalensis, $C$. erecta e $T$. diuretica o herbicida na dose de 2.400 g i.a. ha ${ }^{-1}$ proporcionou, aos $21 \mathrm{DAP}$, níveis de controle de $8,25,8,5$ e 7,25 na escala, respectivamente (Tabela 1). Os valores de 8,25 e 8,5, de acordo com a escala visual de nível de controle, são classificados como aceitáveis. O valor de 7,25 é classificado na escala como mínimo aceitável, o que corresponde de 71 a $80 \%$ de controle da planta daninha. Contudo, foram estatisticamente iguais. Esses resultados se confirmaram aos 50 DAP e assemelharam-se àqueles obtidos por Tozani et al. (1995) em trabalho com a cultura de arroz de sequeiro, no qual se observou que houve controle eficiente de trapoeraba quando se utilizaram doses de diuron de $800,1.600$ e $2.400 \mathrm{~g}$ i.a ha ${ }^{-1}$ em pós emergência. Marcondes et al. (1994) conduziram experimentos na cultura do café, em que observaram que o herbicida diuron nas doses de 1.600 e 3.200 g i.a. ha ${ }^{-1}$ alcançou a eficiência de controle de $100 \%$ sobre $C$. virginica.

$\mathrm{O}$ diuron mostrou-se com fitotoxicidade intensa (7,0 na escala) aos 21 DAP (Tabela 2).
Esse fato pode ser explicado pela não seletividade do produto para o café em fase de implantação no campo. Aos 50 DAP a fitotoxicidade foi considerada fraca. No entanto, Marcondes et al. (1994) não verificaram sintomas de fitotoxicidade para a cultura do café ao utilizar herbicida à base de diuron nas doses de 1.600 e $3.200 \mathrm{~g}^{\text {i.a ha }}{ }^{-1}$.

O herbicida acetochlor é recomendado para aplicação em pré-emergência das plantas daninhas (Jansen, 2005). No presente trabalho, apesar de ter sido aplicado em pós-emergência das espécies de trapoeraba, na dose de 2.700 g i.a. ha ${ }^{-1}$, esse herbicida alcançou, aos 21 DAP, o nivel de controle aceitável sobre C. benghalensis e mínimo aceitável sobre C. erecta, sendo semelhantes estatisticamente. No entanto, não houve controle satisfatório sobre $T$. diuretica, sendo considerado muito fraco para esta espécie, diferindo estatisticamente das demais. Aos 50 DAP, a escala de controle indicou mínimo aceitável para C. benghalensis e aceitável para C. erecta. Esses resultados reforçam os observados por Osipe et al. (1997) em experimento na cultura do café, em que houve controle eficiente da trapoeraba ao se usar acetochlor nas doses de 1,5, 2,0, 2,5 e 3,0 L ha ${ }^{-1}$. O herbicida acetochlor mostrou excelente controle de Commelina sp. em trabalho desenvolvido por Rocha \& Silva (1999) nas doses de 2,0, 3,0 e 4,0 L ha-1, quando aplicado em pós-emergência

A Tabela 2 mostra que o tratamento com o metribuzin e com acetochlor causou fitotoxicidade às plantas jovens de café, pois de acordo com a escala, os valores 8,75 e 8,0 (21 DAP) são considerados altos, demonstrando fitotoxicidade severa, porém esta fitotoxcidade causada pelo acetochlor não diferiu da causada pelo diuron. Aos 50 DAP, o herbicida que mais fitotoxicidade causou às plantas de café foi o metribuzin.

Esses resultados corroboram os encontrados por Rocha \& Silva (1999), que observaram que a aplicação de acetochlor diretamente sobre os cafeeiros provocou fitotoxidade, que foi reduzida aos 40 dias após a aplicação. Neste estudo foi observada redução da fitotoxidade, pois aos 50 DAP a escala de fitotoxidade foi considerada fraca $(4,00)$. Os resultados obtidos com o uso do herbicida acetochlor não se assemelham aos de Adegas (2000), que concluíram 
que o acetochlor é seletivo para a cultura do café, podendo ser usado em pós-emergência desta.

O nivel de controle das espécies tratadas com a mistura de fluazifop-p-butil + fomesafen $\left(180+225\right.$ g i.a ha ha $\left.^{-1}\right)$ foi classificado na escala com valor 1 , ou seja, a porcentagem de controle variou de 0 a $10 \%$, sendo considerado nulo, igualando-se à testemunha, onde não foi aplicado nenhum herbicida, tanto aos 21 quanto aos 50 DAP (Tabela 1). As misturas diuron + paraquat $\left(250+500\right.$ g i.a. ha $\left.{ }^{-1}\right)$, atrazine + metolachlor $\left(1.400+2.100 \mathrm{~g}\right.$ i.a. ha $\left.{ }^{-1}\right)$ e fluazifop-p-butil + fomesafen $(180+$ $225 \mathrm{~g}$ i.a. $\mathrm{ha}^{-1}$ ) foram consideradas com fitotoxicidade nula tanto aos 21 quanto aos 50 DAP. O herbicida 2,4-D e a mistura de 2,4-D + picloram causaram danos mínimos à lavoura (Tabela 2).

Tabela 1 - Níveis de controle de Commelina benghalensis, C. erecta e Tripogandra diuretica em função de diferentes tratamentos com herbicidas aos 21 e 50 DAP

\begin{tabular}{|c|c|c|c|c|c|c|}
\hline \multirow{2}{*}{ Tratamento } & \multicolumn{2}{|c|}{ C. benghalensis } & \multicolumn{2}{|c|}{ C. erecta } & \multicolumn{2}{|c|}{ T. diuretica } \\
\hline & $21 \mathrm{DAP}$ & 50 DAP & $21 \mathrm{DAP}$ & 50 DAP & 21 DAP & $50 \mathrm{DAP}$ \\
\hline fluazifop-p-butil + fomesafen & 1,25 a C & 1,00 a D & 1,00 a D & 1,00 a D & 1,00 a D & 1,00 a D \\
\hline paraquat + diuron & $4,50 \mathrm{ab} \mathrm{B}$ & 4,00 a C & $3,75 \mathrm{~b} \mathrm{C}$ & 4,00 a C & $6,00 \mathrm{a} \mathrm{AB}$ & $6,50 \mathrm{~b} \mathrm{ABC}$ \\
\hline atrazine + metolachlor & 8,00 a A & 7,75 a A & $6,25 \mathrm{~b} \mathrm{AB}$ & 7,00 a $\mathrm{AB}$ & $7,25 \mathrm{ab} \mathrm{AB}$ & 7,75 a A \\
\hline $2,4-\mathrm{D}$ & $4,25 \mathrm{a} \mathrm{B}$ & 4,50 a BC & 3,75 a C & 4,00 a C & 5,00 a BC & 4,75 a BC \\
\hline $2,4-\mathrm{D}+$ picloram & 7,00 a A & 7,25 a A & $7,75 \mathrm{a} \mathrm{AB}$ & 7,75 a A & $7,25 \mathrm{a} \mathrm{AB}$ & 7,25 a A \\
\hline diuron & 8,25 a A & 8,50 a A & 8,50 a A & 7,75 a A & $7,25 \mathrm{a} A B$ & 7,75 a A \\
\hline metribuzin & 7,50 a $\mathrm{A}$ & $6,50 \mathrm{ab} \mathrm{AB}$ & $5,50 \mathrm{~b} \mathrm{BC}$ & $5,00 \mathrm{~b} \mathrm{BC}$ & 8,25 a A & $7,00 \mathrm{a} \mathrm{AB}$ \\
\hline glyphosate (WG) & 7,50 a A & 8,00 a A & $5,75 \mathrm{~b} \mathrm{BC}$ & $6,25 \mathrm{a} \mathrm{ABC}$ & 7,75 a A & 7,75 a A \\
\hline glyphosate (CS) & $3,00 \mathrm{~b} \mathrm{BC}$ & $3,75 \mathrm{~b} \mathrm{C}$ & 7,00 a $\mathrm{AB}$ & $6,75 \mathrm{a} \mathrm{AB}$ & $1,00 \mathrm{c} \mathrm{D}$ & $1,00 \mathrm{c} \mathrm{D}$ \\
\hline acetochlor & 8,00 a A & 7,75 a A & $7,75 \mathrm{a} \mathrm{AB}$ & 8,00 a A & $3,25 \mathrm{~b} \mathrm{D}$ & $4,25 \mathrm{~b} \mathrm{C}$ \\
\hline testemunha & 1,00 a C & 1,00 a D & 1,00 a D & 1,00 a D & 1,00 a D & 1,00 a D \\
\hline
\end{tabular}

Médias seguidas por letras minúsculas distintas, na linha (comparar 21 e 50 DAP separadamente), diferem entre si a 5\% de significância pelo teste de Tukey. Médias seguidas por letras maiúsculas distintas, na coluna, diferem entre si a $5 \%$ de significância pelo teste de Tukey. Níveis de controle: classe 1 (0 a 10\%) - nulo, classe 2 (11 a 20\%) - fraquíssimo, classe 3 (21 a 30\%) - muito fraco, classe 4 (31 a $40 \%)$ - fraco, classe 5 (41 a 50\%) - médio, classe 6 (51 a 60\%) - insuficiente, classe 7 (61 a 70\%) - mínimo aceitável, classe 8 (71 a 80\%) - aceitável, classe $9(81$ a $90 \%)$ - bom e classe 10 (91 a 100\%) - muito bom.

Tabela 2 - Massa seca da parte aérea (MSP Aérea), massa seca do sistema radicular (MSS Radicular), diâmetro do caule, número de folhas, estatura das mudas de café e níveis de fitotoxicidade aos 21 e 50 DAP

\begin{tabular}{|c|c|c|c|c|c|c|c|}
\hline \multirow{2}{*}{ Tratamento } & \multirow{2}{*}{$\begin{array}{c}\text { MSP } \\
\text { Aérea (g) }\end{array}$} & \multirow{2}{*}{$\begin{array}{c}\text { MSS } \\
\text { Radicular (g) }\end{array}$} & \multirow{2}{*}{$\begin{array}{c}\text { Diâmetro do } \\
\text { caule }(\mathrm{mm})\end{array}$} & \multirow{2}{*}{$\begin{array}{l}\text { Número de } \\
\text { Folhas }\end{array}$} & \multirow{2}{*}{$\begin{array}{c}\text { Estatura } \\
(\mathrm{cm})\end{array}$} & \multicolumn{2}{|c|}{ Fitotoxidade } \\
\hline & & & & & & $21 \mathrm{DAP}$ & 50 DAP \\
\hline fluazifop-p-butil + fomesafen. & $28,0 \mathrm{abc}$ & $6,6 \mathrm{abc}$ & $5,9 \mathrm{a}$ & $29,7 \mathrm{ab}$ & $41,3 \mathrm{ab}$ & $1,00 \mathrm{~d}$ & $1,00 \mathrm{~d}$ \\
\hline paraquat + diuron & $31,5 \mathrm{ab}$ & $5,9 \mathrm{bc}$ & $4,6 \mathrm{abc}$ & $29,7 \mathrm{ab}$ & $37,5 \mathrm{ab}$ & $1,75 \mathrm{~d}$ & $1,25 \mathrm{~cd}$ \\
\hline atrazine + metolachlor & $33,8 \mathrm{a}$ & $7,9 \mathrm{ab}$ & $5,7 \mathrm{ab}$ & $29,7 \mathrm{ab}$ & $39,4 \mathrm{ab}$ & $1,00 \mathrm{~d}$ & $1,00 \mathrm{~d}$ \\
\hline $2,4-\mathrm{d}$ & $14,4 \mathrm{ef}$ & $1,7 \mathrm{~d}$ & $4,2 \mathrm{bc}$ & $20,5 \mathrm{bcd}$ & $30,1 \mathrm{~b}$ & $3,75 \mathrm{c}$ & $2,00 \mathrm{~cd}$ \\
\hline $2,4-\mathrm{d}+$ picloram & $21,5 \mathrm{cde}$ & $4,3 \mathrm{~cd}$ & $4,5 \mathrm{abc}$ & 20,7 bcd & $35,0 \mathrm{ab}$ & $5,00 \mathrm{c}$ & $2,00 \mathrm{~cd}$ \\
\hline diuron & $10,1 \mathrm{fg}$ & $2,4 \mathrm{~d}$ & $4,7 \mathrm{abc}$ & $18,2 \mathrm{~d}$ & $38,4 \mathrm{ab}$ & $7,00 \mathrm{~b}$ & $4,00 \mathrm{~b}$ \\
\hline metribuzin & $4,4 \mathrm{~g}$ & $3,6 \mathrm{~cd}$ & $3,8 \mathrm{c}$ & $12,5 \mathrm{~d}$ & $29,9 \mathrm{~b}$ & $8,75 \mathrm{a}$ & $7,00 \mathrm{a}$ \\
\hline glyphosate (WG) & $24,0 \mathrm{bcd}$ & $4,9 \mathrm{bcd}$ & $4,3 \mathrm{abc}$ & $28,0 \mathrm{abc}$ & $34,6 \mathrm{ab}$ & $4,00 \mathrm{c}$ & $3,25 \mathrm{bc}$ \\
\hline glyphosate (CS) & $30,1 \mathrm{abc}$ & $6,3 \mathrm{abc}$ & $4,8 \mathrm{abc}$ & $32,0 \mathrm{a}$ & $36,4 \mathrm{ab}$ & $4,00 \mathrm{c}$ & $2,75 \mathrm{bc}$ \\
\hline acetochlor & $19,1 \mathrm{de}$ & $3,7 \mathrm{~cd}$ & $4,4 a b c$ & $19,5 \mathrm{~cd}$ & $34,2 \mathrm{ab}$ & $8,00 \mathrm{ab}$ & $4,00 \mathrm{~b}$ \\
\hline testemunha & $34,5 \mathrm{a}$ & $9,5 \mathrm{a}$ & $5,9 \mathrm{a}$ & $34,7 \mathrm{a}$ & $45,4 \mathrm{a}$ & $1,00 \mathrm{~d}$ & $1,00 \mathrm{~d}$ \\
\hline
\end{tabular}

Médias seguidas por letras distintas, na coluna, diferem entre si a 5\% de significância pelo teste de Tukey. Níveis de fitoxicidade: classe 1 (0 a 10\%) - nulo, classe 2 (11 a 20\%) - mínimo, classe 3 (21 a 30\%) - muito fraco, classe 4 (31 a $40 \%$ ) - fraco, classe 5 (41 a 50\%) - sensível, classe 6 (51 a 60\%) - médio, classe 7 (61 a 70\%) - intenso, classe 8 (71 a 80\%) - severo, classe 9 ( 81 a $90 \%)$ - muito severo e classe 10 (91 a 100\%) - morte, dano total. 
O tratamento atrazine + metolachlor foi considerado aceitável para o controle de C. benghalensis aos 21 DAP, diferindo estatisticamente do controle de $C$. erecta. Aos 50 DAP, o controle de $C$. benghalensis foi considerado mínimo aceitável, igualando-se estatisticamente aos controles de $C$. erecta e $T$. diuretica (Tabela 1). Chikoye et al. (2005) consideram a espécie $C$. benghalensis suscetível a essa mistura, o que foi confirmado pelos dados obtidos. O crescimento de $T$. diuretica foi afetado pelo uso de atrazine + metolachlor, e o nível de controle foi considerado mínimo aceitável nas duas épocas de avaliação (Tabela 1). A mistura não apresentou fitotoxidade para a cultura, igualando-se à testemunha que não recebeu tratamento (Tabela 2).

O nivel de controle proporcionado pelo tratamento $2,4-\mathrm{D}+$ picloram $(480+130$ g i.a. ha-1 $)$ foi considerado como mínimo aceitável para as três espécies de trapoeraba aos 21 e 50 DAP, não havendo diferenças estatísticas (Tabela 1). As plantas de café tratadas com essa mistura mostraram-se sensiveis aos $21 \mathrm{DAP}$, porém as plantas se recuperaram e aos 50 DAP a fitotoxidade foi considerada mínima (Tabela 2).

O tratamento com metribuzin (720 g i.a. ha ${ }^{-1}$ ), aos 21 DAP, proporcionou nível de controle mínimo aceitável a aceitável para $C$. benghalensis e $T$. diuretica, não havendo diferenças estatísticas. Esse resultado difere dos encontrados por Christoffoleti et al. (2006), que afirmaram que o metribuzin foi ineficiente no controle de $C$. benghalensis. O nivel de controle de $C$. erecta aos 21 DAP foi considerado insuficiente. Aos 50 DAP, o nível de controle foi estatisticamente igual para as três espécies (Tabela 1).

O glyphosate (1.440 g i.a. ha ${ }^{-1}$, na formulação de grânulos autodispersíveis, obteve classificação de 7,5 e 7,75 para $C$. benghalensis e $T$. diuretica, respectivamente, sendo considerado, na escala, como mínimo aceitável, e nível de controle médio para $C$. erecta, aos 21 DAP (Tabela 1). Aos 50 DAP, não houve diferenças estatísticas entre os niveis de controle apresentados pelas espécies de trapoeraba.

Ainda, observando a Tabela 1, nota-se que a espécie $C$. benghalensis foi controlada por diuron, atrazine + metolachlor, acetochlor, glyphosate WG, metribuzin e 2,4-D + picloram, variando o nivel de controle de mínimo aceitável a aceitável, não diferindo estatisticamente, aos 21 DAP. Os herbicidas paraquat + diuron, 2,4-D e glyphosate SC tiveram o mesmo nível de controle sobre $C$. benghalensis, variando o controle de muito fraco a fraco, sendo semelhante estatisticamente. Carvalho et al. (2005) observaram que a mistura de paraquat + diuron foi eficaz no controle de C. benghalensis - superior a $70 \%$. O herbicida fluazifop-p-butil + fomesafen não controlou C. benghalensis, igualando-se em nivel de controle à testemunha onde não foi utilizado nenhum herbicida. Aos 50 DAP, os herbicidas que melhor tiveram efeito no controle de C. benghalensis foram atrazine + metolachlor, 2,4-D + picloram, diuron, metribuzin, glyphosate WG e acetochlor.

A espécie $C$. erecta foi melhor controlada pelos herbicidas diuron, 2,4-D + picloram, acetochlor, glyphosate CS e atrazine + metolachlor, posto que os valores alcançados na escala variaram de 7,0 a 8,5, aos 21 DAP. Esses valores correspondem ao minimo aceitável ou aceitável, com resultados de controle de até 80\%. De La Vega et al. (2000) obtiveram 100\% de mortalidade de $C$. erecta utilizando glyphosate, e Zapparoli et al. (2007) alcançaram $90 \%$ de controle de outra espécie da família Commelinaceae (C. diffusa) com esse herbicida. Aos 50 DAP, os melhores resultados foram obtidos com atrazine + metolachlor, 2,4-D + picloram, diuron, glyphosate WG, glyphosate CS e acetochlor.

A espécie $T$. diuretica foi melhor controlada pelos herbicidas metribuzin, glyphosate, diuron, atrazine + metolachlor, $2,4-\mathrm{D}+$ picloram e paraquat + diuron, não havendo diferenças significativas de controle entre esses produtos sobre essa espécie, tanto aos 21 quanto aos 50 DAP.

O glyphosate na dose utilizada, tanto na formulação de concentrado solúvel (CS) ( $1.170 \mathrm{~g}$ i.a. ha $\mathrm{h}^{-1}$ ) quanto na formulação de grânulos autodispersiveis em água (WG) (1.440 g i.a. ha-1), mostrou fitotoxicidade fraca (4,0 na escala) aos 21 DAP. Em trabalho com mudas de café com um ano de idade, Ronchi et al. (1999) verificaram que o glyphosate causou toxicidade superior a $90 \%$ em aplicação dirigida na linha da cultura, utilizando bicos de pulverização de jato plano. 
Observa-se que aos 50 DAP os efeitos fitotóxicos do herbicida sobre as plantas foram reduzidos.

Na Tabela 2, pode-se observar que os tratamentos com metribuzin, diuron, 2,4-D, 2,4-D + picloram, acetochlor e glyphosate WG afetaram o crescimento, interferindo no acúmulo de massa da parte aérea das mudas de café, se comparados à testemunha. Os demais tratamentos não diferiram estatisticamente da testemunha.

Ao analisar a massa seca do sistema radicular, nota-se que todos os herbicidas que reduziram a taxa de crescimento da parte aérea também a reduziram na parte radicular. Entretanto, esse parâmetro avaliado não diferiu da testemunha em relação aos herbicidas atrazine + metolachlor, fluazifop-p-butil + fomesafen e glyphosate CS.

O diâmetro do caule das plantas foi afetado pela ação dos herbicidas 2,4-D e metribuzin, pois, ao reduzirem a taxa de crescimento, houve redução no desenvolvimento do caule das plantas, se comparadas com a testemunha. O diâmetro do caule das plantas tratadas com os demais herbicidas/misturas não apresentou diferenças estatísticas em relação às plantas não tratadas.

O número de folhas das mudas de café foi afetado pelos herbicidas metribuzin, diuron, acetochlor, 2,4-D e 2,4-D + picloram, os quais causaram queda no número de folhas. Os demais herbicidas apresentaram número de folhas igual ao da testemunha.

A estatura das plantas jovens de cafeeiro foi alterada apenas pelos herbicidas metribuzin e 2,4-D, quando comparados com a testemunha.

O metribuzin, 2,4-D e diuron foram os herbicidas que causaram maiores prejuízos às características de crescimento da muda de café. Esse resultado corrobora os trabalhos de Ronchi \& Silva (2003), que observaram que o metribuzin apresenta fitotoxicidade muito forte às plantas jovens de café.

$\mathrm{O}$ diuron afetou a taxa de crescimento, interferindo no acúmulo de biomassa da parte aérea e do sistema radicular e no número de folhas, já que ele atua inibindo o processo fotossintético, provocando clorose e necrose nas folhas. A massa seca da parte aérea e do sistema radicular e o número de folhas das plantas tratadas com 2,4-D e com a mistura de 2,4-D + picloram foram inferiores aos da testemunha. O diâmetro do tronco e a estatura das plantas também foram menores nas plantas que foram pulverizadas com 2,4-D, pois esse herbicida atua, preferencialmente, nas regiões meristemáticas da parte aérea e radicular, provocando tumores.

Assim, a espécie C. benghalensis foi melhor controlada pelos herbicidas diuron, 2,4-D + picloram, atrazine + metolachlor, metribuzin, glyphosate WG e acetochlor. A espécie C. erecta foi controlada pelos herbicidas diuron, 2,4-D + picloram, atrazine + metolachlor, glyphosate CS e acetochlor. Os herbicidas diuron, 2,4-D + picloram, atrazine + metolachlor, metribuzin, glyphosate WG e paraquat + diuron foram os que melhor controlaram $T$. diuretica. Os herbicidas metribuzin, diuron e acetochlor mostraram-se mais fitotóxicos para a cultura do café em fase de formação. O diâmetro do caule e a estatura foram afetados pelos herbicidas metribuzin e 2,4-D. As características de crescimento da muda de café foram mais afetadas pelo herbicida metribuzin.

\section{LITERATURA CITADA}

ADEGAS, F. S. Eficiência e seletividade de herbicidas aplicados na cultura do café em formação. In: CONGRESSO BRASILEIRO DA CIÊNCIA DAS PLANTAS DANINHAS, 22., 2000, Foz do Iguaçu. Resumos... Foz do Iguaçu: SBCPD, 2000. p. 343.

CARVALHO, J. A. et al. Efeitos da mistura pronta de ametryne mais simazine com glyphosate e paraquat no controle de plantas daninhas na cultura do cafeeiro. R. Bras. Herbic., v. 4, n. 2, p. 86-91, 2005

CHIKOYE, D.; UDENSI, U. E.; LUM, A. F. Evaluation of a new formulation of atrazine and metolachlor mixture for weed control in maize in Nigeria. Crop Prot., v. 24, n. 11, p. 1016-1020, 2005

CHRISTOFFOLETI, P. J. et al. Carfentrazone-ethyl aplicado em pós-emergência para o controle de Ipomea spp. e Commelina benghalensis na cultura da cana-de-açúcar. Planta Daninha, v. 24, n. 1, p. 83-90, 2006.

COMPANHIA NACIONAL DE ABASTECIMENTO CONAB. Acompanhamento da safra brasileira café: safra 2008, quarta estimativa, dezembro/2008. Brasília: 2008. Disponível em: < http://www.conab.gov.br/conabweb/ download/safra/Boletim.pdf>. Acesso em: 05 mar. 2009. 
DE LA VEGA, M. H. et al. Controle de Commelina erecta L. con herbicidas postemergentes com el objectivo de su uso en cultivos de soja transgénica. Planta Daninha, v. 18, n. 1, p. $51-56,2000$

DEUBER, R. Ciência das plantas daninhas: fundamentos. Jaboticabal: FUNEP, 1992. $431 \mathrm{p}$.

DIAS, G. F. S.; ALVES, P. L. C. A.; DIAS, T. C. S. Brachiaria decumbens suprime o crescimento inicial de Coffea arabica. Sci. Agric., v. 61, n. 6, p. 579-83, 2004.

DIAS, T. C. S.; ALVES, P. L. C. A.; LEMES, L. N. Períodos de interferência de Commelina benghalensis na cultura do café recém-plantada. Planta Daninha, v. 23, n. 3, p. 397-404, 2005.

JANSEN, A. E. Plant protection in coffee recommendations for the common code for the coffee community-initiative. Eschborn: Deutsche Gesellschaft für Technische Zusammenarbeit (GTZ), 2005. 65 p.

MARCONDES, D. S. et al. Controle de plantas daninhas dicotiledôneas após arruação na cultura do cafeeiro. In: CONGRESSO BRASILEIRO DE PESQUISAS CAFEEIRAS, 20., 1994, Guarapari. Anais... Guarapari: MAA/PROCAFÉ,1994. p. 44-47.

MONQUERO, P. A.; CURY, J. C.; CHISTOFFOLETI, P. J. Controle pelo glyphosate e caracterização geral da superfície foliar de Commelina benghalensis, Ipomoea hederifolia, Richardia brasiliensis e Galinsoga parviflora.

Planta Daninha, v. 23, n. 1, p. 123-132, 2005.

OLIVEIRA, A. R.; FREITAS, S. P.; VIEIRA, H. D. Interferência de trapoerabas no desenvolvimento de mudas de café. Agronomia, v. 39, n. 1-2, p. 17-21, 2005.

OSIPE, R.; MAROCHI, A. I.; MARINHO, E. O. Avaliação da eficácia e seletividade do acetochlor aplicado em préemergência na cultura do café. In: CONGRESSO BRASILEIRO DA CIÊNCIA DAS PLANTAS DANINHAS, 21., 1997, Caxambu. Resumos... Caxambu: SBCPD, 1997. p. 286.

RAMOS, H. H.; DURIGAN, J. C. Avaliação da eficiência da mistura pronta de glyphosate $+2,4-\mathrm{D}$ no controle da Commelina virginica L. em citros. Planta Daninha, v. 14, n. 1, p. 33-41, 1996

ROCHA, D. C. et al. Efeito de herbicidas sobre quatro espécies de trapoeraba. Planta Daninha, v. 25, n. 2 , p. 359-364, 2007.
ROCHA, M. A. M.; SILVA, A. E. S. Validação do uso de Fist $\mathrm{CE}$ em áreas de café conillon para controle das principais plantas daninhas no Estado do Espírito Santo. In: CONGRESSO BRASILEIRO DE PESQUISAS CAFEEIRAS, 25., 1999, Franca. Anais... Franca: MAA/ PROCAFÉ, 1999. p. 195-197.

RONCHI, C. P.; SILVA, A. A.; FERREIRA, L. R. Efeito dos bicos Turbo Floodjet e espuma na eficácia e seletividade do glyphosate em aplicação dirigida na linha de café (Coffea arabica $\mathrm{L}$.) com um ano de idade. In: SIMPÓSIO DE INICIAÇÃO CIENTÍFICA, 8., 1999, Viçosa. Resumos... Viçosa, MG: Universidade Federal de Viçosa, 1999. p. 225

RONCHI, C. P.; SILVA, A. A. Effects of weed species competition on the growth of young coffee plants.

Planta Daninha, v. 24, n. 3, p. 415-423, 2006.

RONCHI, C. P.; SILVA, A. A. Tolerância de mudas de café a herbicidas aplicados em pós-emergência. Planta Daninha, v. 21, n. 3 , p. $421-426,2003$.

RONCHI, C. P.; SILVA, A. A.; FERREIRA, L. R. Manejo de plantas daninhas em lavouras de café. Viçosa, MG: Suprema, 2001

RONCHI, C. P. et al. Acúmulo de nutrientes pelo cafeeiro sob interferência de plantas daninhas. Planta Daninha, v. 21, n. 2, p. 219-227, 2003.

SULLIVAN, P. A.; DONOVAN, J. T. Interaction between glyphosate and various herbicides for broadleaved weed control. Weed Res., v. 20, n. 4, p. 255-260, 2006.

TOLEDO, S. V.; MORAES, M. V.; BARROS, I. Efeito da freqüência de capinas na produção do cafeeiro. Bragantia, v. 55, n. 2 , p. $317-324,1996$.

TOZANI, R. et al. Emprego de prometryne e diuron na cultura do arroz de sequeiro (Oryza sativa L.). R. Univ. Rural, Ser. Ci. Vida, v. 17, n. 1, p. 31-37, 1995.

TUFFI SANTOS, L. D. et al. Efeito do glyphosate sobre a morfoanatomia das folhas e do caule de Commelina diffusa e C. benghalensis. Planta Daninha, v. 22, n. 1, p. 101-107, 2004.

VARGAS, L. et al. Resistência de plantas daninhas a herbicidas. Viçosa, MG: Universidade Federal de Viçosa, 1999. $131 \mathrm{p}$.

ZAPPAROLI, R. A. et al. Resposta das trocas gasosas e eficiência no controle de Commelina diffusa sob diferentes doses de glyphosate. In: SIMPÓSIO INTERNACIONAL SOBRE GLYPHOSATE, 1., 2007, Sete Lagoas. Anais... Sete Lagoas: SBCP/Embrapa CNPMS, 2007. p. 11-14 (Boletim Informativo, v.15, n.3). 